\title{
Itinerários da participação na gestão de escolas públicas de educação básica
}

\author{
Itineraries of the participation in management of public schools of basic \\ education \\ Itinerarios de la participación en gestión de escuelas públicas de educación \\ basica
}

ELTON LUIZ NARDI

Resumo: $\mathrm{O}$ trabalho tem por objetivo analisar opções normativo-institucionais relacionadas à gestão democrática do ensino público e ações delineadas por escolas de Educação Básica visando à participação. Com base no exame de documentos legais de um conjunto de sistemas municipais de ensino e do levantamento, por meio de questionários, de ações propostas e declaradas por escolas vinculadas a esses sistemas, conclui pela existência de um quadro instável de condições favoráveis à democratização da gestão escolar, embora as evidências sinalizem para o reconhecimento do valor político da participação.

Palavras-chave: Gestão democrática; escola pública; participação; sistemas municipais de ensino.

\begin{abstract}
The purpose of this work is to analyze the normative-institutional options related to democratic management of public education and actions built by schools of basic education aiming to participate. It is based on the examination of legal documents of a set of municipal systems of education, and a survey through questionnaires and actions proposed and declared by schools connected to these systems. It concludes that there is an unstable framework condition favorable to the democratization of the school management, although the evidences indicate the recognition of the political value of participation.
\end{abstract}

Keywords: Democratic management; public school; participation; municipal school system.

Resumen: El trabajo tiene por objetivo analizar opciones normativoinstitucionales relacionadas a la gestión democrática de la enseñanza pública y acciones delineadas por escuelas de educación básica visando la participación. Con base en el examen de documentos legales de un conjunto de sistemas municipales de enseñanza y del levantamiento, por medio de cuestionarios, de acciones propuestas y declaradas por escuelas vinculadas a esos sistemas, concluí por la existencia de un cuadro inestable de condiciones favorables a la democratización de la gestión escolar, aunque las evidencias señalen para el reconocimiento del valor político de la participación.

Palabras clave: Gestión democrática; escuela pública; participación; sistemas municipales de enseñanza. 


\section{INTRODUÇÃO}

Considerada peça fundamental da gestão democrática, a participação direta dos atores sociais em processos decisórios sobre assuntos de interesse comum segue sendo, no entendimento dos seus cultores, tanto um ideal como um desafio que se renova e se reconfigura no curso das transformações sociais, políticas e culturais da sociedade.

Vale dizer que, na cena social, acumulamos importantes experiências que tocam a questão da participação, como foi o movimento pela redemocratização do país, posto em marcha nos anos de 1980. No entanto, também acumulamos duras experiências vividas à sombra do autoritarismo e, portanto, ao largo de uma dinâmica em que fosse possível "tomar parte" dos processos políticos que implicam o destino do país. Ainda assim, é possível dizer que, no leito da história, soubemos colher lições dos períodos de restrição das liberdades ou mesmo de recusa a elas.

A educação, profundamente implicada com as transformações aqui referidas, também foi e continua sendo palco de tensões e desafios que atravessam a questão da democracia no país, embora nem sempre embalada pelos mesmos princípios e objetivos, haja vista a correlação de forças que opera em favor de projetos distintos de sociedade e, portanto, de educação pública.

É nesse contexto que segue a aposta na participação com vistas a finalidades coletivas e, como mencionado, onde também se preservam e se renovam forças contrárias a seu desempenho em prol dessas finalidades. Daí que, omnipresente nos discursos político, normativo e pedagógico (LIMA, 2003), seja tanto convocada com vistas à intervenção dos atores sociais no espaço público de produção político-educacional (KRAWCZYK, 2008) como proclamada para escamotear sua ausência (PARO, 1997), ao passo em que outras formas funcionais a interesses não coletivos tomam lugar e buscam produzir conformações. Nesse caso, seguindo Bourdieu (2010), referimo-nos à linha do fazer ver e fažer crer, útil à relação entre quem exerce o poder e quem a ele está submetido. Ganham lugar, por exemplo, políticas e medidas com função simbólica de reforço à participação e à autonomia da escola, com o fim de produzir a legitimação do controle pelo centro.

Assim posto, de uma perspectiva crítico-compreensiva da construção de condições com potencial para fazer avançar a democratização da gestão escolar enquanto projeto político, o presente trabalho tem por objetivo analisar opções normativo-institucionais relacionadas à gestão democrática do ensino público e ações delineadas por escolas de Educação Básica visando à participação. 
Para tanto, tomamos por base empírica elementos normativos e ações propostas por escolas públicas de Educação básica com vistas ao fortalecimento da participação de suas comunidades escolares, de modo a explorarmos tensões, sintonias e tendências informadas na relação entre quadros normativos de sistemas de ensino e planejamentos delineados por escolas pertencentes a esses sistemas. Como pano de fundo, consideramos a influência de velhos traços de uma cultura política de ordem patrimonial (FAORO, 1987) que, preservando-se ao longo do tempo, renova-se por meio de práticas autoritárias e conservadoras, hábeis em atropelar valores democráticos. Consideramos, também, o fato de a escola pública estar sendo convocada a se concentrar na implementação de ações com potencial para produzir resultados educacionais que informam determinado referencial de qualidade, haja vista a operação de políticas de regulação da educação que conferem centralidade à avaliação como instrumento de gestão (SOUSA, 2003; KRAWCZYK; VIEIRA, 2008).

Considerando esse quadro referencial, recorremos a um conjunto de achados de duas pesquisas realizadas no período de 2010 a 2012, por meio das quais foram levantados dados relacionados à gestão democrática e à promoção da participação na gestão de escolas públicas de redes municipais de uma mesorregião do estado de Santa Catarina.

Da primeira pesquisa ${ }^{1}$, cujo objetivo foi analisar as condições estabelecidas institucionalmente pelos governos municipais para a promoção da gestão democrática do ensino público, foram considerados dados obtidos por meio de exame documental, mais precisamente das leis de institucionalização dos sistemas municipais de ensino na área de abrangência da investigação.

Já em relação à segunda pesquisa ${ }^{2}$, foram considerados os resultados parciais de uma investigação que buscou avaliar a potencialidade e o alcance das estratégias e ações deflagradas por escolas públicas visando à melhoria da qualidade educacional, cujo quadro amostral foi constituído por 18 escolas públicas de ensino fundamental, situadas na mesma mesorregião do estado e vinculadas aos sistemas de ensino focalizados na primeira pesquisa. Nesse caso, a delimitação da amostra de municípios foi pautada por critérios de porte populacional e de

\footnotetext{
1 A pesquisa contou com apoio financeiro da Fundação de Amparo à Pesquisa e Inovação do Estado de Santa Catarina (FAPESC) e do Conselho Nacional de Desenvolvimento Científico e Tecnológico (CNPq), por meio do Programa Institucional de Bolsas de Iniciação Científica (PIBIC).

2 A pesquisa foi realizada com apoio do Programa Observatório da Educação (OBEDUC), da Coordenação de Aperfeiçoamento de Pessoal de Nível Superior (CAPES)/Brasil.
} 
localização geográfica, garantida a representação de todas as microrregiões da área de abrangência mesorregional, enquanto a do quadro de escolas observou a inclusão de uma unidade de cada município amostrado. ${ }^{3}$

Consoante o objetivo do trabalho, iniciamos com algumas reflexões em torno do campo temático enfocado, associadas a elementos que permitem sua contextualização. Na sequência, apresentamos e analisamos os dados colhidos, tendo à frente o propósito de compor um quadro indicativo em termos de normas e ações coligidas, de modo a permitir o apontamento de tendências em termos de promoção da participação como recurso de gestão na escola pública da mesorregião pesquisada. Por fim, tecemos considerações com vistas a uma síntese conclusiva.

\section{NOTAS SOBRE PARTICIPAÇÃO E GESTÃO DEMOCRÁTICA DA ESCOLA PÚBLICA}

A gestão escolar não foge, a exemplo de outros domínios da política educacional, à influência da velha cultura política brasileira que, com seus valores autoritários (AZEVEDO, 2000), promove renovadamente uma dominação política de ordem patrimonial. Conforme Faoro (1987), nessa linha de denominação, o Estado é governado na perspectiva da propriedade, com a autoridade construindo e preservando poderes pessoais que demarcam um modelo político mais resistente do que a periodicidade dos governos.

$\mathrm{Na}$ síntese de Ianni (2004), sobre a história do Brasil moderno e a simbolização de rupturas, retrocessos e aberturas ao longo do século XX, embora se tenham processado modificações na sociedade em termos sociais, econômicos, políticos e culturais, não significa que elas sempre tenham sido para melhor, favoráveis aos interesses da maioria do povo.

Nessa linha de pensamento, a despeito de certos matizes modernistas surgidos com o tempo, as colunas que sustentam os expedientes patrimonialistas não são postas a perigo. Daí continuarem ganhando vez e força as atitudes favoritistas que embalam a troca de vantagens na esfera política, acentuando a indistinção entre o público e privado.

Essa dinâmica, inclusive por não ser claramente apreendida na consciência popular, renova-se e se preserva ao longo do tempo, filiando-se a ela boa parte das mazelas que atravessam a gestão pública no país. Dessa frágil apreensão, também

3 Para a delimitação do quadro amostral das escolas em cada município, foram considerados como critérios: ser a escola de ensino fundamental com menor Índice de Desenvolvimento da Educação Básica (IDEB) no ano de 2007 e ofertar, preferencialmente, o Ensino Fundamental completo. 
resultam consequências à qualidade política do controle social, pela sociedade, sobre a ação do Estado.

Referimo-nos, pois, ao valor da participação política, entendendo-a como via de aperfeiçoamento das condições de democratização da gestão escolar, ainda que sejam recorrentes os recursos e as estratégias de simplificação dessa via, principalmente por aqueles segmentos que se nutrem da sua ausência. Participação aqui entendida como o envolvimento das pessoas na construção da realidade político-social (BORDENAVE, 1985) - base dos mecanismos que dão concretude à gestão democrática (MENDONÇA, 2000) - e como ação política em processos decisórios decorridos da identificação de problemas e demandas, acompanhamento, controle, fiscalização e avaliação (LIMA, 2003), constituindo um processo de aprendizado e de luta política, característico da forma democrática de gestão (DOURADO, 2000).

Como sabemos, no contexto da abertura política dos anos de 1980, as proposições para a gestão da educação enfocaram mais incisivamente o fator "compromisso político", fruto de uma luta inscrita nos movimentos mais amplos pela democratização do país. Decorre desse contexto a crescente valorização de condições favoráveis à participação, o que inclui a constituição de espaços e mecanismos institucionalizados ${ }^{4}$, alguns deles contemplados na Constituição Federal de 1988. Conforme anota Krawczyk (2008), a gestão constituía parte do debate político mais amplo sobre o direito de participação da sociedade civil como condição de uma cidadania ativa.

$\mathrm{Na}$ linha das conquistas alcançadas por esses movimentos, o art. 206, inciso VI, da Constituição Federal, firmou o princípio da gestão democrática do ensino público, que também figura na atual Lei de Diretrizes e Bases da Educação Nacional (LDB), ainda que esta não tenha fixado diretrizes mais específicas sobre o tema, como se verifica nos seguintes dispositivos:

\footnotetext{
Art. $3^{\circ}$. O ensino será ministrado com base nos seguintes princípios: [...] VIII - gestão democrática do ensino público, na forma desta Lei e da legislação dos sistemas de ensino; [...] Art. 14. Os sistemas de ensino definirão as normas da gestão democrática do ensino público na Educação Básica, de acordo com as suas peculiaridades e conforme os seguintes princípios: I - participação dos profissionais da educação na elaboração do projeto pedagógico da escola; II - participação das comunidades escolar e local em conselhos escolares ou equivalentes. [...] Art. 15. Os sistemas de ensino assegurarão às unidades escolares públicas de educação básica que os integram progressivos graus de autonomia pedagógica e administrativa e de gestão financeira, observadas as normas gerais de direito financeiro público.
}

4 Dentre esses espaços e mecanismos, destacam-se os conselhos, a escolha de dirigentes escolares e as instâncias de deliberação coletiva sobre assuntos de interesse público, como fóruns, conferências e seminários. 
Não tendo a LDB avançado no delineamento de regras específicas, a tarefa foi mesmo transferida aos sistemas de ensino. ${ }^{5}$ De acordo com o art. 14 , as normas de gestão democrática a serem estabelecidas pelos sistemas devem atender às peculiaridades locais, sem perder de vista o princípio da participação, como na elaboração do projeto político-pedagógico da escola e em conselhos escolares ou equivalentes.

Não menos expressivo, outro aspecto contextual diz respeito às políticas educacionais recentes que focalizam o tema da qualidade da educação, apostando em sua melhoria e em processos avaliativos que possibilitem traduzi-la quantitativamente. Esse enfoque tem repercutido fortemente na gestão escolar, campo em que vêm-se processando muitas das mudanças na área educacional a que temos assistido nas últimas décadas (OLIVEIRA, 2008; KRAWCZYK, 2005, 2008).

$\mathrm{Na}$ síntese de Laval (2004, p. 13), trata-se de um movimento em que o Estado "[...] fica conhecido por definir as grandes perspectivas e avaliar, a posteriori, os resultados de uma gestão mais autônoma, com a ajuda de um sistema estatístico rigoroso, que deve permitir a 'pilotagem' das unidades locais e periféricas" Uma sistemática que se, de um lado, tem relação com serviços de medida, avaliação e informação educacional, de outro, está relacionada com o fortalecimento do "Estado avaliador" e com a vinculação de princípios educativos à política administrativa gerencial (FREITAS, 2007) ${ }^{6}$, posto que, conforme Afonso (2009, este Estado passa a admitir "[...] a lógica do mercado, através da importação para o domínio público de modelos de gestão privada, com ênfase nos resultados e nos produtos dos sistemas educativos" (p. 49).

Com base em análises de Neave (1988), para Whitty, Power e Halpin (1998), esse protagonismo do Estado avaliador demarca outra função e oportunidade à avaliação, diferente do que ocorrera noutros tempos, e outra relação entre o Estado e o sistema educativo:

\footnotetext{
Em primeiro lugar, substitui as preocupações predominantes pela qualidade do provimento e a igualdade de acesso e oportunidades. Em segundo lugar, ao centrar se nos resultados, redefine a finalidade da educacão em relacão à economía, em vez de com a demanda individual. Em terceiro lugar, proporciona um poderoso instrumento para dirigir as instituições. (p. 56 - tradução nossa)
}

5 A Lei no 13.005, de 26 de junho de 2014, que aprova o Plano Nacional de Educação (PNE) para o período 2014-2024, também aponta para essa direção, embora fixe o prazo de dois anos, contados da publicação da lei, para o disciplinamento da gestão democrática por parte dos estados, do Distrito Federal e dos municípios. 6 A reforma educacional levada a efeito nos anos de 1990, como parte do processo de reforma do aparelho do Estado, revelou uma orientação diversa da que vinha sendo defendida pelos setores comprometidos com a escola pública democrática e de qualidade para todos. Desde uma orientação de gestão educacional pautada na lógica empresarial, as políticas públicas no país tenderam a dar lugar à racionalidade econômica e instrumental nos processos de gestão, em sintonia com requerimentos de mercado.

654 - RBPAE - v. 31, n. 3, p. 649 - 666 set./dez. 2015 
É na linha dessa tendência de aferição do desenvolvimento educacional que situamos a implantação do IDEB, em 2007. Um índice que cumpre o papel de informar o quanto as escolas e as redes avançam nas metas educacionais de qualidade e que opera um processo de indução da qualificação almejada em nível central. Como se sabe, tendo o Estado alçado o tema da qualidade da educação a uma posição central e de responsabilidade de toda a sociedade (BRASIL, 2007), o tom prioritário desse tema foi transposto à legislação educacional, servindo de reforço à implementação de uma série de políticas públicas do setor.

Com a vigência desse referencial de qualidade e seu amplo processo de afirmação pelas políticas educacionais e setores da sociedade, as escolas são desafiadas à implementação de ações capazes de repercutir na produção de melhores índices (NARDI; SCHNEIDER; RIOS, 2014), embora continuem, em razão de seus compromissos político-pedagógicos, conclamadas a observar as singularidades e objetivos educativos e sociais nutridos por suas comunidades, o que inclui o desafio histórico de avançar na democratização da gestão escolar.

Estaria esse desafio sendo enfrentado com o mesmo vigor com que nossas escolas operam - ou são instadas a operar - a produção de melhores índices educacionais, não raro associados a incentivos ou sanções (SOUSA, 2008, 2009)? Essa é discussão que, tendo em mira condições, vias e possibilidade em termos de democratização da gestão da escola pública de educação básica, no contexto aqui referido, buscamos realizar a partir de agora.

\section{MAIS OU MENOS PARTICIPAÇÃO? ENTRE NORMAS E AÇÕES DA ESCOLA}

Com o intuito de ampliar a discussão sobre condições de aperfeiçoamento do processo de democratização da gestão da escola pública de Educação Básica, tomamos por base os achados das duas pesquisas mencionadas. Conforme assinalado, ambas as pesquisas tiveram como campo empírico uma mesorregião de Santa Catarina, da qual fazem parte 118 municípios. Juntos, esses municípios representam um quarto do território do estado e somam uma população de aproximadamente 1.200.000 habitantes.

Relativamente à primeira pesquisa, levada a efeito nos anos de 2010 e 2011, foram considerados dados obtidos em exame documental. Nesse caso, foram levantados princípios da gestão democrática, bem como dados sobre espaços e mecanismos de participação formalizados na legislação dos sistemas municipais de ensino da mesorregião. Do total de municípios, $84 \%$ já haviam institucionalizado seu sistema. ${ }^{7}$ 
À conta dessa frente de investigação, foi possível sistematizar um quadro de opções políticas quanto à democratização da gestão educacional nos municípios, opções essas informadas por princípios constantes da legislação examinada. O Quadro 1 informa a frequência dos oito princípios mais presentes na base documental consultada.

\section{Quadro 1 - Princípios da gestão democrática do ensino público mais frequentes nas leis dos sistemas municipais de ensino da mesorregião Oeste catarinense - 2010 e 2011}

\begin{tabular}{|c|c|c|}
\hline & Princípios & Frequência \\
\hline I. & $\begin{array}{l}\text { Participação dos profissionais de educação na elaboração do projeto político- } \\
\text { pedagógico da escola. }\end{array}$ & $78,8 \%$ \\
\hline II. & $\begin{array}{c}\text { Participação da comunidade escolar e local em conselhos escolares ou } \\
\text { equivalentes. }\end{array}$ & $69,7 \%$ \\
\hline III. & $\begin{array}{l}\text { Progressivos graus de autonomia pedagógica, administrativa e de gestão } \\
\text { financeira da escola. }\end{array}$ & $60,1 \%$ \\
\hline IV. & $\begin{array}{l}\text { Participação da comunidade escolar na tomada de decisão no âmbito das } \\
\text { respectivas unidades escolares e do sistema municipal de ensino. }\end{array}$ & $15,2 \%$ \\
\hline V. & Transparência nos mecanismos pedagógicos, administrativos e financeiros. & $14,1 \%$ \\
\hline VI. & $\begin{array}{c}\text { Respeito à autonomia de organização de pais, professores, servidores e } \\
\text { estudantes. }\end{array}$ & $14,1 \%$ \\
\hline VII. & Realização de eleição direta para diretores de escola. & $13,1 \%$ \\
\hline VIII. & $\begin{array}{c}\text { Ação coletiva de planejamento, formulação, implementação e avaliação das } \\
\text { políticas educacionais. }\end{array}$ & $12,1 \%$ \\
\hline
\end{tabular}

Fonte: Legislação municipal.

De acordo com os dados do quadro, a participação dos atores escolares e o reforço à autonomia da escola figuram na legislação como ideias-força da gestão democrática. Presidida por princípios que enfocam esses atributos, as condições normativas delineadas no âmbito dos sistemas pesquisados mantêm sintonia com aqueles princípios registrados na atual LDB, aos quais os sistemas estaduais e municipais de ensino estão submetidos, embora lhes tenha sido encomendada a ampliação de tal ordenamento por meio da legislação local.

Esse é, pois, um aspecto central a ser destacado, posto que a esperada ampliação do leque de princípios de gestão democrática, por meio da regulamentação dos sistemas municipais de ensino, não se confirma no conjunto de documentos examinados, como se pode evidenciar pela acentuada queda do percentual que informa a frequência dos princípios seguintes aos três primeiros.

Como parte desse mesmo cenário e em sintonia com o quadro descrito, decorre igualmente o não alargamento do conjunto de espaços e mecanismos de participação em nível de sistema municipal. Atentos ao âmbito mais específico da escola, o exame da legislação possibilitou identificar que dois espaços ou 
mecanismos se destacam no conjunto levantado, conforme podemos visualizar no Quadro 2.

Quadro 2 - Espaços e mecanismos de participação definidos na legislação dos sistemas de ensino dos municípios da mesorregião Oeste catarinense -2010 a 2011

\begin{tabular}{|lr|c|}
\hline & Espaços/mecanismos de participação & Frequência \\
\hline I. & Conselho Municipal de Educação & $100 \%$ \\
\hline II. & Projeto Político-Pedagógico & $92,9 \%$ \\
\hline III. & Conselhos escolares ou equivalentes & $78,8 \%$ \\
\hline IV. & Conferência, Fórum ou Seminário de Educação & $17,2 \%$ \\
\hline V. & Outros conselhos & $16,2 \%$ \\
\hline VI. & Eleição de diretores & $10 \%$ \\
\hline VII. & Escolha de diretores (participação no processo por via não eleitoral) & $6,1 \%$ \\
\hline
\end{tabular}

Fonte: Legislação municipal.

Como assinalado, a maior frequência de menções ao "projeto políticopedagógico" e aos "conselhos escolares ou equivalentes" concorda com os princípios de 1 a 3, identificados no Quadro 1, afora o fato de também serem apontados pela LDB. Característica comum, esses espaços/mecanismos não contam, na normatização, com detalhamentos que possam conferir mais clareza em termos de estrutura e funcionamento, de modo a contribuir para uma maior efetividade dessas instâncias no campo da prática, situação corrente em cerca de $90 \%$ das leis municipais examinadas.

De modo geral, a recusa a uma ampliação desses espaços e mecanismos, na esteira do que anunciam os princípios mais frequentes, soa restritivo em termos de possibilidades de reforço à democratização da gestão das escolas, especialmente se considerarmos que outras vias têm sido apontadas como potenciais a esse processo, dentre as quais, por exemplo, a eleição direta para diretores. Esse mecanismo, conforme se observa no Quadro 2, ainda ocupa posição periférica no rol das opções político-institucionais do conjunto de sistemas municipais de ensino pesquisados. ${ }^{8}$

A partir desse quadro normativo, que parece pôr em suspeição o compromisso local com o alargamento das condições de democratização da gestão do ensino público, buscamos, em um segundo momento, deslocar as lentes para ações e estratégias deflagradas no âmbito das escolas, visando a identificar iniciativas relacionadas à promoção da participação e ao fortalecimento de

8 Embora realcem o direito dos membros da comunidade escolar à participação em processos de escolha dos diretores escolares, algumas leis não associam a participação a processos de eleição direta. 
instâncias destinadas a promovê-la, aqui identificadas como espaços e mecanismos. Para tanto, recorremos a dados colhidos dos achados da segunda pesquisa, em sua primeira fase de levantamento (2010 a 2012). As 18 escolas enfocadas constituem, portanto, uma representação do conjunto de sistemas municipais de ensino enfocado na primeira pesquisa.

Seriam as escolas protagonistas de ações indicativas de avanços na promoção e dinamização da participação e de espaços e mecanismos afins, comparativamente ao perfil normativo informado nos documentos? Nestes tempos em que são incisivamente submetidas à avaliação da qualidade do ensino que oferecem, estariam essas mesmas escolas menos vigilantes à construção de processos mais democráticos em seu interior?

Essas são questões que mobilizaram nossa análise, constituindo-se, em síntese, em um exercício de leitura do poder de ação conjunta e criativa dos atores escolares (APPLE, BEANE, 2001), pela possibilidade de sê-lo por meio de dinâmicas de atuação orientadas por princípios democráticos mais incisivos do que aqueles demarcados nas leis dos seus sistemas de ensino. Conforme assinalam Apple e Beane (2001), diz respeito a um "processo criativo de buscar formas de ampliar horizontal e verticalmente os valores da democracia" (p. 30), reconhecendo-se que a participação da comunidade, como todo processo democrático, é um caminho que se faz ao caminhar e que demanda reflexão acerca dos obstáculos e potencialidades no campo da ação (PARO, 1997).

Assim, quanto às iniciativas delineadas pelas escolas pesquisadas, foram mapeadas 274 ações previstas ou implementadas no âmbito das instituições de ensino no período de 2010 a 2012. ${ }^{9}$ Do total de ações, 11,7\% são mais diretamente afetas ao desenvolvimento de práticas participativas dos atores escolares na gestão da escola e à promoção de espaços ou mecanismos institucionais de participação. O Gráfico 1 ilustra os dados da frequência das ações mais referidas e das menos referidas pelas escolas no âmbito de 11 eixos explorados no estudo. ${ }^{10}$

9 O levantamento foi realizado por meio de questionários elaborados com o objetivo de captar propostas de ações e estratégias prioritárias, traçadas pelas escolas a cada período.

10 Os eixos foram distribuídos em quatro dimensões: infraestrutura escolar (condições físicas e recursos pedagógicos); gestão escolar (planejamento, recursos humanos, recursos financeiros e parcerias); formação dos profissionais da Educação Básica (formação inicial e formação continuada); e práticas pedagógicas (organização escolar, organização didático-pedagógica e avaliação da aprendizagem). 
Gráfico 1 - Frequência de ações traçadas pelas escolas em diferentes eixos das dimensões pesquisadas e de ações que implicam a participação em espaços ou em mecanismos de participação - Etapa 2010-2012

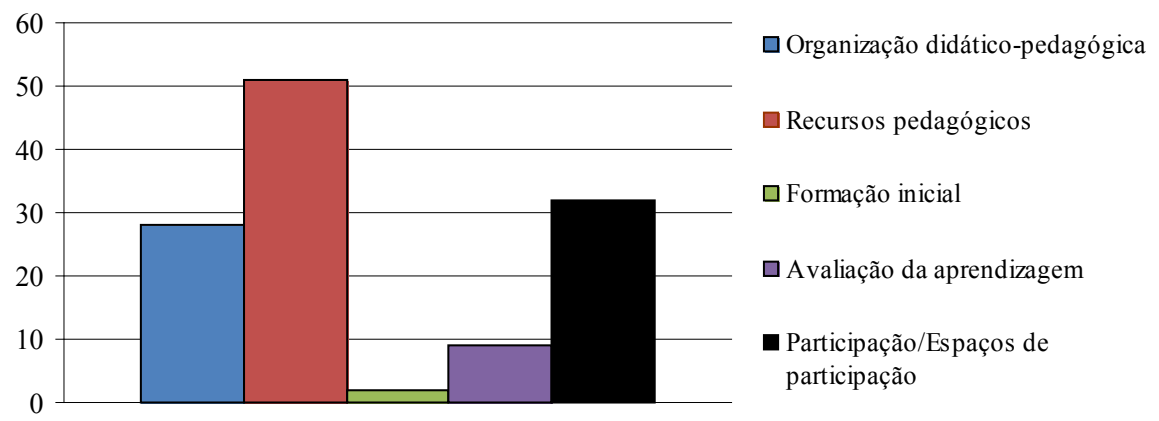

Fonte: Questionários do projeto OBEDUC.

De acordo com os dados do gráfico, na comparação entre ações traçadas no âmbito dos eixos que aportaram o maior número de iniciativas no período (organização didático-pedagógica e recursos pedagógicos) e os eixos com o menor número de iniciativas (avaliação da aprendizagem e formação inicial), percebemos que é significativa a quantidade de ações que, de alguma forma, tem relação com a participação e a promoção de espaços ou mecanismos de participação.

Essa constatação é relevante na medida em que a formulação e a implementação de ações voltadas à promoção da participação da comunidade escolar, com vistas à democratização da gestão, não constituem um eixo específico da pesquisa, embora se tenha depositado certa expectativa de que iniciativas dessa ordem constassem dos eixos que integram a dimensão "gestão escolar".

De acordo com o Gráfico 2, duas das quatro dimensões eleitas pela pesquisa acolheram o maior número de ações que informam iniciativas relacionadas à promoção ou valorização da participação e de espaços e mecanismos a promovêla. 
Gráfico 2 - Número de ações relacionadas à participação e a espaços e mecanismos de participação, eleitas pelas escolas por eixo e dimensão Etapa 2010 a 2012

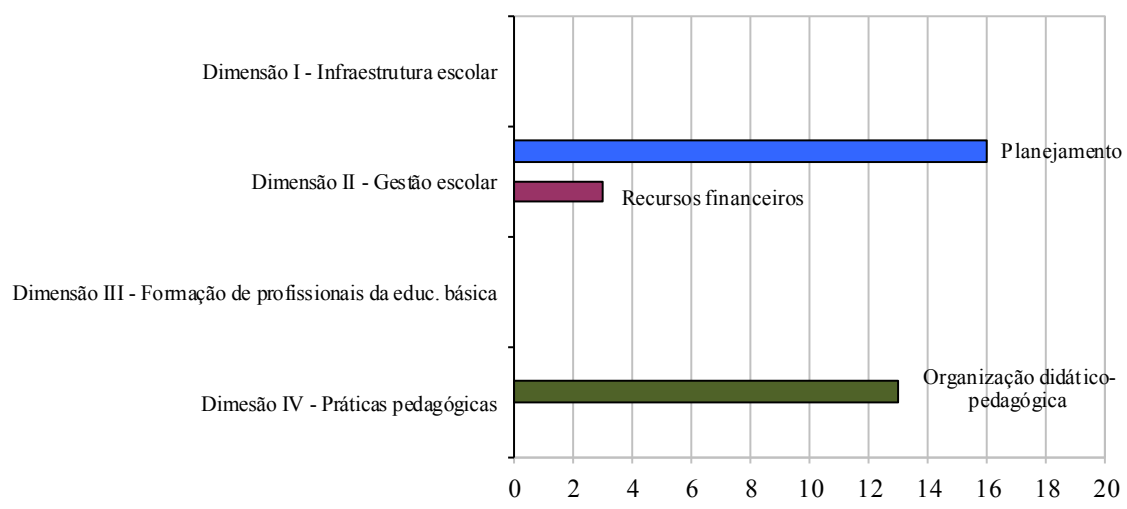

Fonte: Questionários do projeto OBEDUC

Conforme se verifica no gráfico, as ações relacionadas à participação e à promoção ou fortalecimento de espaços e mecanismos de participação estão aportadas nas dimensões II e IV, destacando-se, pela quantidade, os eixos "planejamento" e "organização didático-pedagógica". O conjunto de ações mapeadas por dimensão e eixo, por meio do qual são sinalizados espaços e mecanismos de participação no âmbito das escolas, encontram-se sistematizadas no Quadro 3. ${ }^{11}$

Quadro 3 - Ações relacionadas à participação e a espaços e mecanismos de participação, eleitas pelas escolas por eixo e dimensão - Etapa 2010-

2012

\begin{tabular}{|c|c|c|}
\hline \multirow{2}{*}{$\begin{array}{c}\text { Dimensão/ } \\
\text { Eixo }\end{array}$} & $\begin{array}{c}\text { Descrição } \\
\text { da ação relacionada à participação }\end{array}$ & $\begin{array}{c}\text { Espaço/mecanismo de } \\
\text { participação destacado }\end{array}$ \\
\hline \multirow{4}{*}{$\begin{array}{l}\text { II-Gestão escolar } \\
\text { Eixo: Planejamento }\end{array}$} & Reformular o projeto político-pedagógico & Projeto político-pedagógico \\
\cline { 2 - 3 } & Planejar coletivamente & \\
\cline { 2 - 3 } & Realizar avaliação institucional & Avaliação institucional \\
\cline { 2 - 3 } & Realizar planejamento e avaliação coletivos & \\
\cline { 2 - 3 } & Construir planos de ação & Conselho escolar \\
\cline { 2 - 3 } & Ativar/reativar o conselho escolar & \\
\hline
\end{tabular}

11 O conteúdo que comunica uma ação que refere um espaço ou mecanismo de participação pode não ter, necessariamente, o espaço ou mecanismo como alvo principal. 
Quadro 3 - Ações relacionadas à participação e a espaços e mecanismos de participação, eleitas pelas escolas por eixo e dimensão - Etapa 20102012

\begin{tabular}{|c|c|c|}
\hline $\begin{array}{l}\text { Dimensãol } \\
\text { Eixo }\end{array}$ & $\begin{array}{c}\text { Descrição } \\
\text { da ação relacionada à participação }\end{array}$ & $\begin{array}{l}\text { Espaço/mecanismo de } \\
\text { participação destacado }\end{array}$ \\
\hline \multirow{3}{*}{$\begin{array}{l}\text { II - Gestão escolar } \\
\text { Eixo: Recursos } \\
\text { financeiros }\end{array}$} & $\begin{array}{l}\text { Decidir com a comunidade escolar a aplicação de } \\
\text { recursos }\end{array}$ & \\
\hline & Acompanhar a aplicação de recursos na escola & \\
\hline & $\begin{array}{c}\text { Submeter a aplicação dos recursos à fiscalização da } \\
\text { Associação de Pais e Professores (APP) }\end{array}$ & $\begin{array}{l}\text { Associação de Pais e } \\
\text { Professores (APP) }\end{array}$ \\
\hline $\begin{array}{c}\text { IV - Práticas } \\
\text { pedagógicas } \\
\text { Eixo: Organização } \\
\text { escolar }\end{array}$ & Implementar o projeto político-pedagógico & Projeto político-pedagógico \\
\hline \multirow{8}{*}{$\begin{array}{c}\text { IV - Práticas } \\
\text { pedagógicas } \\
\text { Eixo: Organização } \\
\text { didático-pedagógica }\end{array}$} & Revisar a proposta pedagógica/curricular & \\
\hline & Construir/desenvolver projetos interdisciplinares & \\
\hline & Organizar as ações pedagógicas & \\
\hline & Realizar planejamento do ensino & \\
\hline & Implementar grupos de estudo & Grupo de estudos \\
\hline & Fortalecer a interação com os pais & \\
\hline & Fortalecer os conselhos de classe & Conselho de Classe \\
\hline & Realizar reuniões com os pais & Assembleia \\
\hline
\end{tabular}

Fonte: Questionários do projeto OBEDUC.

A partir do exposto no Quadro 3, podemos constatar que, entre as ações mapeadas, há diversas indicações de espaços e mecanismos de participação, constituindo um conjunto que, em linhas gerais, responde ao quadro de instâncias identificado nos documentos, embora se apresente um pouco mais alargado por dar alguma visibilidade a outros espaços e mecanismos, e alguns deles já consolidados nas escolas, como é o caso do Conselho de Classe, da APP e das assembleias. Embora sinalizada por algumas escolas, a avaliação institucional não mereceu menção na legislação examinada.

Como se pode verificar, a maior convergência em termos de instâncias identificadas nos dados da primeira e da segunda pesquisa situa-se em torno de dois espaços ou mecanismos de participação: o projeto político-pedagógico e o conselho escolar - este último notadamente menos expressivo no rol de ações declaradas pelas escolas.

Acompanham essa maior convergência os três princípios mais frequentes declarados no Quadro 1, que sublinham a participação e a autonomia da escola na sua relação com o projeto político-pedagógico e o conselho escolar. Em boa medida, essa convergência também se estende ao conjunto de ações das escolas anotado na coluna central do Quadro 3. 
Importa, por fim, considerar que as ações mais frequentes relacionadas à participação e a espaços ou mecanismos de participação (mencionadas por três ou mais escolas) foram, em ordem decrescente: reformular o projeto políticopedagógico, planejar coletivamente, revisar a proposta pedagógica/curricular e realizar a avaliação institucional. Também cosiderar que, à frente dos demais, o projeto político-pedagógico figura como o mecanismo mais presente no conjunto de ações traçadas pelas escolas com vistas à melhoria da qualidade da educação, correspondendo a $27 \%$ das ações destinadas a promover a participação na escola. ${ }^{12}$

\section{CONSIDERAÇÕES FINAIS}

De modo geral, os achados das duas pesquisas conduzem ao delineamento de um quadro instável em termos de reforço às condições de democratização da gestão das escolas da mesorregião, além de informarem a coexistência de interpretações e formulações que expressam diferentes concepções de natureza política e social da gestão democrática, que vão de posturas de participação restrita e funcional a perspectivas de participação efetiva e cidadã (DOURADO, 2000).

De um lado, o plano normativo revela uma concentração em princípios e em espaços e mecanismos de participação que, embora caros à democratização da gestão, já se encontram determinados pela legislação nacional. A nosso ver, esse dado constitui indício de que o reforço às condições de democratização, como tarefa estabelecida pela LDB aos sistemas de ensino, não tem sido uma iniciativa efetivamente abraçada na mesorregião, podendo, inclusive, motivar suspeita sobre o efetivo compromisso político dos dirigentes com aqueles princípios, espaços e mecanismos que constam da norma. Corrobora essa suspeição a prevalecente ausência de detalhamento acerca dos espaços e mecanismos determinados nas leis, uma situação que, a nosso ver, pode dar margem a dinâmicas não comprometidas com valores verdadeiramente democráticos.

De outro lado, as ações traçadas pelas escolas trazem significativa marca da participação da comunidade educativa, razão pela qual parece-nos possível dizer que, no contexto da escola, a via da participação constitui uma aposta, mesmo em tempos em que as instituições são chamadas a concentrar esforços noutras frentes, como na produção de resultados oficiais que, na atualidade, seguem demarcando a qualidade da educação básica.

Ainda no caso das ações delineadas pelas escolas, embora tenha sido possível verificar que o leque de instâncias de participação e a ênfase em algumas

12 Outras ações levantadas ( $22 \%$ do total) ocuparam posição menos expressiva na agenda das escolas investigadas, já que, na maioria dos casos, foram mencionadas apenas uma vez. 
delas se assemelhem muito ao apontado nos documentos, o que poderia levarnos a concluir que se trata de processo tímido ou pouco criativo de ampliação de valores democráticos, não se pode ignorar a ingerência política e administrativa nas escolas, muitas vezes patrocinada por valores alheios aos nutridos em seu interior. Ademais, é preciso lembrar que a promoção de vias de participação na escola não foge aos efeitos de um contexto marcado por complexa pluralidade de interesses, identidades e objetivos que mobilizam os atores escolares, o que inclui distintas expectativas sobre a dinâmica democrática (MOISÉS, 1995).

Em suma, ainda que diferentes circunstâncias e desafios como os apontados neste trabalho tenham influenciado o empenho das escolas pesquisadas na promoção de melhores condições de participação, o estudo parece-nos referendar a viabilidade e o reconhecimento do valor político dessa via para a democratização da gestão escolar.

\section{REFERÊNCIAS}

AFONSO, Almerindo Janela. Avaliação educacional: regulação e emancipação. 4. ed. São Paulo: Cortez, 2009.

APPLE, Michael; BEANE, James. O argumento por escolas democráticas. In: . (Org.). Escolas democráticas. 2. ed. São Paulo: Cortez, 2001. p. 9-43.

AZEVEDO, Janete Maria Lins de. O estado, a política educacional e a regulação do setor educação no Brasil: uma abordagem histórica. In: FERREIRA, Naura Syria Carapeto; AGUIAR, Márcia Angela da Silva (orgs.). Gestão da educação: impasses, perspectivas e compromissos. São Paulo: Cortez, 2000. p. 17-42.

BORDENAVE, Juan E. Diaz. O que é participação? 3. ed. São Paulo: Brasiliense, 1985.

BOURDIEU, Pierre. O poder simbólico. Tradução Fernando Tomaz, $14^{\mathrm{a}}$ ed. Rio de Janeiro: Bertrand Brasil, 2010.

BRASIL. Constituição da República Federativa do Brasil, 1988. Brasília: Senado Federal, 1988. Disponível em: http://www.planalto.gov.br/ccivil_03/ constituicao/constituicao.htm. Acesso em: 15 ago. 2015.

. Decreto n ${ }^{\circ}$ 6.094, de 24 de abril de 2007. Dispõe sobre a implementação do Plano de Metas Compromisso Todos pela Educação, pela União Federal, em 
regime de colaboração com Municípios, Distrito Federal e Estados, e a participação das famílias e da comunidade, mediante programas e ações de assistência técnica e financeira, visando a mobilização social pela melhoria da qualidade da educação básica. Diário Oficial da União. Brasília: Imprensa Nacional, 25 de abril, 2007.

. Lei no ${ }^{\circ}$ 13.005, de 25 de junho de 2014. Aprova o Plano Nacional de Educação - PNE e dá outras providências. Diário Oficial União, , Edição Extra, no 120-A, Seção 1, p. 1-8 Poder Executivo, Brasília: Imprensa Nacional 26 jun. 2014.

DOURADO, Luiz Fernandes. A escolha de dirigentes escolares: políticas e gestão da educação no Brasil. In: FERREIRA, Naura Syria Carapeto (org.) Gestão democrática da educação: atuais tendências, novos desafios. $2^{a}$ ed. São Paulo: Cortez, 2000. p. 77-95.

. Lei no. 9.394, de 20 de dezembro de 1996. Estabelece as diretrizes e bases da educação nacional. Diário Oficial [da] República Federativa do Brasil, Seção 1, p. 27833-27841Poder Executivo, Brasília: Imprensa Nacional, 21 dez. 1996.

FAORO, Raymundo. Os donos do poder: formação do patronato político brasileiro. 2 v. $7^{\text {a }}$. ed. São Paulo: Globo, 1987.

FREITAS, Luiz Carlos de. Eliminação adiada: o caso das classes populares no interior da escola e a ocultação da má (qualidade) do ensino. Educação \& Sociedade, Campinas, v. 28, n. 100, p. 965-987, Edição Especial, out. 2007.

IANNI, Octavio. Pensamento social no Brasil. Bauru: EDUSC, 2004.

KRAWCZYK, Nora Ruth. Políticas de regulação e mercantilização da educação: socialização para uma nova cidadania? Educação \& Sociedade, Campinas, v. 26, n 92. p.799-819, out. 2005.

. Em busca de uma nova governabilidade na educação. In: OLIVEIRA, Dalila Andrade; ROSAR, Maria de Fatima Felix (orgs.). Política e gestão da educação. 2. ed. Belo Horizonte: Autêntica, 2008. p. 61-74.

; VIEIRA, Vera Lucia. A reforma educacional na América Latina nos anos de 1990: uma perspectiva histórico-sociológica. São Paulo: Xamã, 2008.

664 - RBPAE - v. 31, n. 3, p. 649 - 666 set./dez. 2015 
LAVAL, Christian. A escola não é uma empresa: o neo-liberalismo em ataque ao ensino público. Londrina: Planta, 2004.

LIMA, Licínio. A escola como organização educativa. 2. ed. São Paulo: Cortez, 2003.

MENDONÇA, Erasto Fortes. A regra e o jogo: democracia e patrimonialismo na educação brasileira. Campinas: LaPlane/FE/UNICAMP, 2000.

MOISÉS, José Álvaro. Os brasileiros e a democracia: bases sócio-políticas da legitimidade democrática. São Paulo: Ática, 1995.

NARDI, Elton Luiz; SCHNEIDER, Marilda Pasqual; RIOS, Mônica Picione Gomes. Qualidade da educação básica: ações e estratégias dinamizadoras. Educação \& Realidade, Porto Alegre, v. 39, n. 2, p. 359-390, abr./jun. 2014.

NEAVE, Guy. On the cultivation of quality, efficiency and enterprise: an overview of recent trends in higher education in Western Europe: 1968-1988. European Journal of Education, v. 23, n. 1/2, p. 7-23, 1988.

OLIVEIRA, Dalila Andrade. Mudanças na organização e na gestão do trabalho na escola, in: OLIVEIRA, Dalila Andrade; ROSAR, Maria de Fatima Felix (Orgs.). Política e gestão da educação. 2. ed. Belo Horizonte: Autêntica, 2008. p. 127145.

PARO, Vitor Henrique. Gestão democrática da escola pública. São Paulo: Ática, 1997.

SOUSA, Sandra M. Zákia L. Possíveis impactos das políticas de avaliação no currículo escolar. Cadernos de Pesquisa, São Paulo, n. 119, p. 175-190, jul. 2003.

Avaliação e carreira do magistério: premiar o mérito? Retratos da Escola, Brasília, v. 3, n.2-3, p. 81-93, jan./dez. 2008.

- Avaliação e gestão da educação básica no Brasil: da competição aos incentivos. In: DOURADO, Luiz Fernandes (Org.). Políticas e gestão da educação no Brasil: novos marcos regulatórios? São Paulo: Xamã, 2009. p. 3145. 
WHITTY, Geoff; POWER, Sally; HALPIN, David. La escuela, el estado y el mercado. Madrid: Morata, 1998.

ELTON LUIZ NARDI é Doutor em Educação pela Universidade do Vale do Rio dos Sinos (Unisinos). Professor Titular do Programa de Pós-Graduação em Educação da Universidade do Oeste de Santa Catarina (Unoesc). E-mail: elton. nardi@unoesc.edu.br

Recebido em outubro de 2015

Aprovado em dezembro de 2015 